\title{
DECREASED PERIFERAL BLOOD DENDRITIC CELLS IN MULTIPLE MYELOMA: THE POTENTIAL ROLE OF IL-6 AND BETA-2-MICROGLOBULIN
}

\author{
Ilina Micheva, Hinko Varbanov, Liana Gercheva \\ Department of Internal Diseases, Medical University of Varna
}

\begin{abstract}
INTRODUCTION: Several studies demonstrate the presence of quantitative and functional abnormalities in the dendritic cell (DC) subsets in patients with multiple myeloma (MM). The inhibitory effect of IL-6, TGF- $\beta$, IL-10 and beta-2-microglobuline (beta-2-MG) is highly suspected.

PURPOSE: The aim of the study was to evaluate the myeloid and plasmacytoid dendritic cells (MDC and PDC) in newly diagnosed patients with MM in correlation with various biological markers.

MATERIALS AND METHODS: Thirty patients with newly diagnosed MM were included in the study. All the laboratory parameters were obtained at the time of diagnosis. Three colour flowcytometry with ILT3/ lin/CD11c was used for the detection of the two peripheral blood dendritic cell (PBDC) subsets. The plasma level of IL6 was detected by ELISA (Standard Curve Range: $2-200 \mathrm{pg} / \mathrm{ml}$ ); the beta-2-MG- by the immunoturbidimetric test.

RESULTS: The median age of patients was 61.5 years (36-89). The mean M-protein concentration was 46.5 $\pm 16.2 \mathrm{~g} / \mathrm{l}$. IgG kappa was detected in 15 patients, IgG lambda-in 4, IgA kappa-in 7, IgA lambda-in 3. The mean level of beta-2-MG was $7.0 \pm 5.7 \mathrm{mg} / 1(1.82-22.49 \mathrm{mg} / \mathrm{l})$; beta-2-MG was used to determine the stage according to the ISS. The mean level of IL6 was $27.73 \pm 21.47 \mathrm{pg} / \mathrm{ml}(4.6-72.5 \mathrm{pg} / \mathrm{ml})$. The percentage of MDC and PDC was significantly lower in the periferal blood of patients with MM in comparison to healthy subjects $(0.08 \% \pm 0.09 \%$ vs $0.21 \% \pm 0.02 \%$ and $0.04 \% \pm 0.03 \%$ vs $0.16 \% \pm 0.01 \%$, respectively). A statistically significant difference was found between the percentage of $M D C$ and PDC in the different stages. There was a negative correlation between MDC and PDC and the levels of beta-2-MG ( $p=0.02$ and $p=0.02)$, as well as between MDC and the IL6 levels $(p=0.04)$. No correlation was found between MDC, PDC, levels of M-protein and the type of paraprotein.
\end{abstract}

CONCLUSION: Our results demonstrate the relationship between peripheral blood DC, IL6 and beta2-MG and confirm the published data for the inhibitory effect of the two factors on DC differentiation and maturation in vitro. The monitoring of beta-2-MG and IL6 may have clinical implication as a predictor of the immune system status as well as for the yield of harvested DCs for vaccination.

Keywords: multiple myeloma, dendritic cells, IL-6, beta-2-MG

\author{
Address for correspondence: \\ Ilina Micheva, $M D, P h D$ \\ Clinic of Hematology, University Hospital "St. Marina" \\ 1 Hristo Smirnenski Str. \\ 9010 Varna, Bulgaria \\ e-mail: ilinamicheva@gmail.com \\ phone: +35952978288
}

Received: May 14, 2014

Accepted: September 10, 2014

\section{INTRODUCTION}

Dendritic cells (DCs) are sparsely distributed bone marrow-derived cells that are continuously produced from haematopoietic stem cells (5). As the most potent antigen-presenting cells, DCs are specialized in the uptake, processing, transport and presentation of antigens to T cells (6). Variations among the tissue distribution, as well as differences in their 
Ilina Micheva, Hinko Varbanov, Liana Gercheva

phenotype and function, indicate the existence of a heterogeneous DC population that in periferal blood $(\mathrm{PB})$ is represented by two subsets, namely the myeloid DC (MDC) precursors and the plasmacytoid DC (PDC) (14). Although their developmental relationship has not been established, it is likely that they represent distinct lineages of functionally diverse immature DCs $(5,8)$. MDC and PDC induce polarization of naïve T cells, driving T-helper 1 (Th1) and Th2 immune response respectively $(9,13)$. Defects in immune response are often reported in patients with multiple myeloma (MM). Dendritic cells (DCs) are key effectors in promoting cellular immunity and are potential vectors for immunotherapy. Contradictory results have been obtained regarding the number, phenotypic status and functionality of DCs from MM patients. Some studies demonstrate that the level of DCs in these patients is normal $(3,10,11)$, while other studies show a reduced number and functional impairment of MM DCs and the inhibitory role of IL-6, TGF- $\beta$, IL-10 is broadly discussed $(1,2,4,7,12)$.

The role of beta-2-MG in the MM pathogenesis is well established. Recently, a new, international classification method was utilized for myeloma prognosis, The International Staging System (ISS), using a combination of serum beta-2-MG and serum albumin for staging the disease. Beta-2-MG is supposed to be a negative regulator of the immune system. An interesting study demonstrates that high serum concentration of the protein inhibits generation of functional monocyte derived dendritic cells in vitro (17).

The aim of the present study was to evaluate the myeloid and plasmacytoid dendritic cells in newly diagnosed patients with MM and search for a correlation with various biological markers such as beta2-MG, Il-6, the type and the amount of paraprotein.

\section{MATERIALS AND METHODS}

\section{Patients}

Thirthy patients with MM, diagnosed at the University Hospital, Varna were studied, 14 males and 16 females, with median age of 61.5 years (range, 36-89 years). Ten healthy volunteers served as controls. Samples of heparinized blood were drawn from patients at the time of diagnosis and before the administration of any treatment. Informed consent was obtained from both patients and normal donors. The mean M-protein concentration was $46.5 \pm 16.2 \mathrm{~g} / \mathrm{l}$.
IgG kappa was detected in 15 patients, IgG lambdain 4, IgA kappa-in 7, IgA lambda-in 3 patients.

\section{Flow cytometric analysis}

Blood DCs were identified by three-colour staining, performed on PBMC, using the following MoAbs: ILT3-PE-cyanin 5 (PC5) (Immunotech, Villepinte, France), CD11c-PE (PharMingen; BD, Erembodegen, Belgium) and fluorescein isothiocyanate (FITC)-labelled MoAbs against lineage markers CD14, CD16, CD19 and CD56 (Immunotech). Cells that were not labelled by these lineage markers were designated as lin $^{-}$.

\section{IL-6 ELISA}

The test was performed using a standard Kit Human IL-6 with Pre-Coated Plate, eBioscience, (Standard Curve Range: $200-2 \mathrm{pg} / \mathrm{ml}$ ) according to the protocol provided.

\section{Serum beta-2-MG}

Beta-2-MG was evaluated in serum from patients with MM using the immunoturbidimetric test.

\section{Statistical analysis}

The data sets were compared by independent two-tailed t-tests. $\mathrm{P}<0.05$ was considered significant. The Pearson correlation test was used to assess linear relationships between samples. SPSS Statistics 17.0 software was used.

\section{RESULTS}

\section{Blood DC reduction in MM patients}

Circulating blood DC subsets were analyzed at diagnosis on $\mathrm{PB}$ mononuclear cells using the lineage markers, CD11c and ILT3. According to the expression of CD11c, two populations of lin $^{-} /$ILT3 $^{+}$ cells were observed: $\operatorname{lin}^{-} / \mathrm{ILT}^{+} / \mathrm{CD} 11 \mathrm{c}^{+}$MDCs and $\mathrm{lin}^{-} / \mathrm{ILT3}^{+} / \mathrm{CD} 1 \mathrm{Cc}^{-}$PDCs (Fig. 1A). In the group of the MM patients, the percentage of both DC subsets was significantly reduced compared to controls (MDC: $0.08 \% \pm 0.09 \%$ vs $0.21 \% \pm 0.02 \%$ and PDC: $0.04 \% \pm 0.03 \%$ vs $0.16 \% \pm 0.01 \%, \mathrm{p}<0.001$ ).

Corelation of MDC and PDC with serum beta-2-MG

The mean level of serum beta-2-MG in patients with $\mathrm{MM}$ was $7.0 \pm 5.7 \mathrm{mg} / \mathrm{l}(1.82-22.49 \mathrm{mg} / \mathrm{l})$. Using this value, the stage of the disease was determined according to ISS. Five patients were in stage I, five in stage II, and twenty in stage III. A statistically significant diference was found between the levels of MDC 


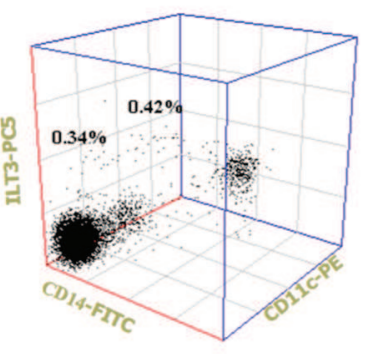

Control

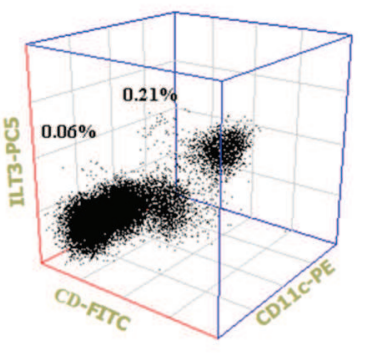

MM
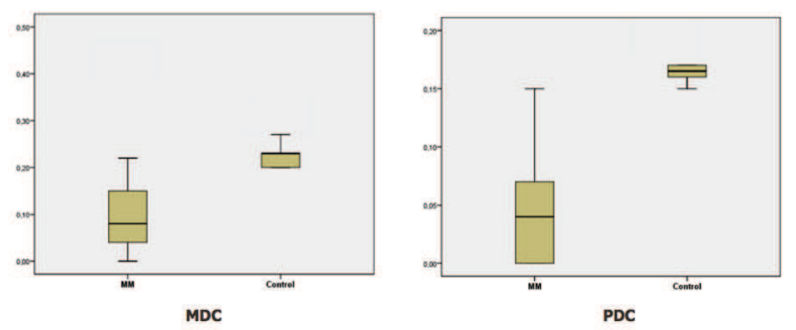

Fig. 1. Examples of the flow cytometric analysis of the circulating DC subsets in a healthy volunteer and an $M M p a-$ tient. Blood DCs were identified by three-colour staining performed on PBMCs using the following MoAbs: ILT-3-PC5, CD11c-PE and FITC-labelled MoAbs against lineage markers CD14, CD16, CD19 and CD56. According to the expression of CD11c, two populations of lin ${ }^{-} / I L T 3^{+}$cells were observed: $\mathrm{inn}^{-} / \mathrm{ILT3}^{+} / \mathrm{CD} 11 \mathrm{c}^{+} \mathrm{MDCs}$ and $\mathrm{lin}^{-} / \mathrm{ILT3}^{+} / \mathrm{CD} 11 \mathrm{c}^{-} \mathrm{PDCs}(\mathrm{A})$. Distribution of the percentage and mean values of PBDCs in healthy donors and MM patients (B).
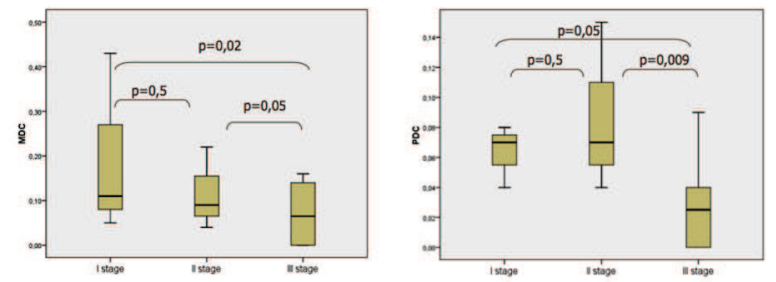

Fig. 2. Statistically significant diference was found between the levels of MDC and PDC in the diferent stages of $M M$

and PDC in the diferent stages (Fig. 2). A negative corelation was found between the serum beta-2-MG and PBDC subsets (Pearson Correlation for MDC and beta-2-MG -0.47, p=0.02, and for PDC and beta2-MG -0.47, $\mathrm{p}=0.02$ ) (Fig. 3).
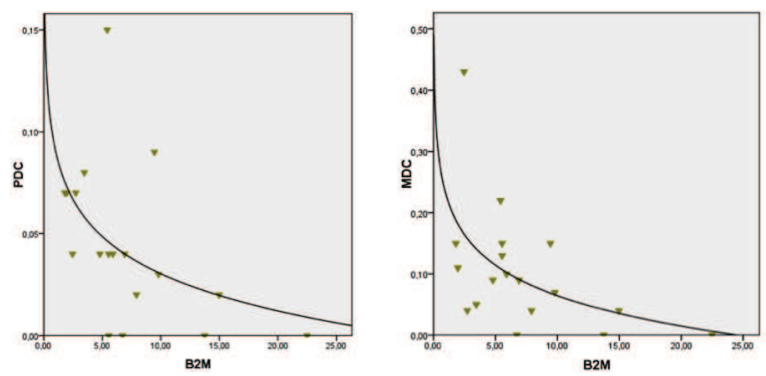

Fig.3. A corelation between the serum beta-2-MG and PBDC subsets. Pearson Correlation for MDC and beta-2$M G(-0,47, p=0,02)$, and for PDC and beta-2-MG (-0,47, $p=0,02)$

\section{Corelation of MDC and PDC with IL-6}

The mean level of Il- 6 was $27.73 \pm 21.47 \mathrm{pg} / \mathrm{ml}$ (4.6-72.5 pg/ml). Based on the hystogram patients were devided in three groups according to the IL- 6 level: $0-20 \mathrm{pg} / \mathrm{ml}, 20-40 \mathrm{pg} / \mathrm{ml}$, and $>40 \mathrm{pg} / \mathrm{ml}$. A statistically significant diference was found between the levels of MDC in the three diferent groups (Fig 4).
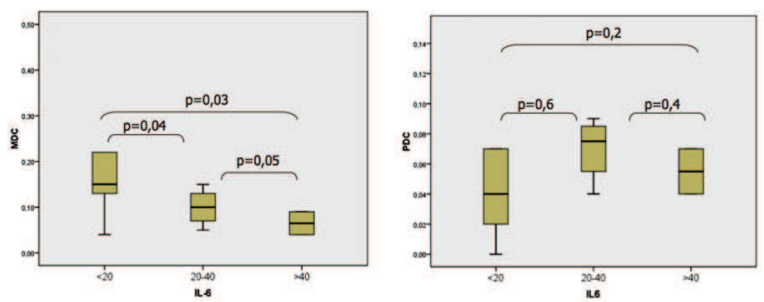

Fig. 4. A comparison between the pecentage of MDC and PDC in the groups defined according to Il-6 level (0-20 pg/ $\mathrm{ml}, 20-40 \mathrm{pg} / \mathrm{ml}$, and $>40 \mathrm{pg} / \mathrm{ml}$ ).

There was a negative correlation between MDC and the IL6 levels (Pearson Correlation -0.48, $\mathrm{p}=0.04$ ). No correlation was found between PDC and IL-6 (Pearson Correlation B2M -0.03, p=0.4) (Fig.5).
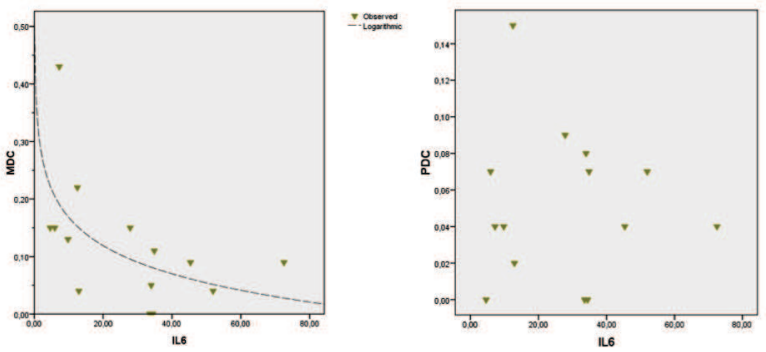

Fig. 5. The correlation between MDC and the IL6 levels (Pearson Correlation -0,48, $p=0,04$ ) and PDC and IL-6 (Pearson Correlation $-0,48, p=0,04$ ). 
No correlation was found between MDC, PDC, levels of M-protein and the type of paraprotein.

\section{DISCUSSION}

In the present study we found that the two PBDC subsets are decreased in patients with newly diagnosed MM. In a similar study, Ratta $\mathrm{M}$ et al. demonstrate that PBDCs from MM patients are not only lower in absolute numbe, but also functionally defective, partially because of IL-6-mediated inhibition of development (12). Another study shows that MM patients have a $50 \%$ reduced blood level of MDC, but a DC-precursor level within normal range. Furthermore, GM-CSF and IL- 4 ex vivo stimulated DC demonstrate an impaired up-regulation of the co-stimulatory molecule CD80 and the adhesion molecule CD54 (4). Hyashy T et al. found that sera from bone marrow of MM patients inhibited induction of DCs, evidenced by both phenotype and only weak stimulation of T-cell proliferation. Anti-vascular endothelial growth factor (anti-VEGF) and/or anti-interleukin 6 (anti-IL-6) antibodies neutralized this inhibitory effect, confirming that VEGF and IL6 , at least in part, mediate immunosuppression in MM patients (7). Our results demonstrate the negative relationship between peripheral blood MDC and IL6 and confirm in vivo the published data for the inhibitory effect of this factor on DC differentiation and maturation in vitro.

There is evidence for the suppressive effect of beta-2-MG on DC generation in vitro (17); however, this effect is only suspected for MM patients. In the present study we show that beta-2-MG negatively correlates with both MDC and PDC in patients with MM.

Various studies have been performed in order to identify the ideal source of DCs from MM patients for use in vaccination approaches $(2,3,11,16)$. The analysis of samples following chemotherapy and transplantation demonstrated an increased expression of HLA molecules, suggesting that this timepoint is optimal for harvest and use in vaccination (1).

In this context the monitoring of beta-2-MG and IL6 may have clinical implication as a predictor of the immune system status during the course of the disease. It may also help to determine the most adequate time point for DCs harvesting for generation of pure, functional, and potentially proliferating DCs for further use in vaccination.

\section{REFERENCES}

1. Brimnes M K, I M Svane, and H E Johnsen. Impaired functionality and phenotypic profile of dendritic cells from patients with multiple myeloma. Clin Exp Immunol., 2006;144(1):76-84.

2. Brown RD, Pope B, Murray A, Esdale W, Sze DM, Gibson J, Ho PJ, Hart D, Joshua D. Dendritic cells from patients with myeloma are numerically normal but functionally defective as they fail to upregulate CD80 (B7-1) expression after huCD40LT stimulation because of inhibition by transforming growth factor-betal and interleukin-10. Blood, 2001;98:2992-8.

3. Butch AW, Kelly KA, Munshi NC. Dendritic cells derived from multiple myeloma patients efficiently internalize different classes of myeloma protein. Exp Hematol., 2001;29(1):85-92.

4. Do TH, Johnsen HE, Kjaersgaard E, Taaning E, Svane IM. Impaired circulating myeloid DCs from myeloma patients. Cytotherapy, 2004;6(3):196-203.

5. Grouard G, Rissoan MC, Filgueira L, Durand I, Banchereau J \& Liu YJ. The enigmatic plasmacytoid $\mathrm{T}$ cells develop into dendritic cells with interleukin (IL)-3 and CD40-ligand. Journal of Experimental Medicine, 1997;185;1101-1111.

6. Hart DNJ. Dendritic cells: unique leukocyte populations which control the primary immune response. Blood, 1997;90:3245-3287.

7. Hayashi T, Hideshima T, Akiyama M, Raje N, Richardson P, Chauhan D, and Anderson KC. Ex vivo induction of multiple myeloma-specific cytotoxic T lymphocytes. Blood, 2003;102(4):1435-42.

8. Kohrgruber N, Haianek N, Groger M, Winter D, Rappersberg K, Schmitt-Egenolf M, Stingel G \& Mauer D. Survival, maturation, and function of CD11c- and CD11c+ peripheral blood dendritic cells are differentially regulated by cytokines. Journal of Immunology, 1999;163:3250-3259.

9. Macatonia SE, Hosken NA, Litton M, Vieira P, Hsieh CS, Culpepper JA, Wysocka M, Trinchieri G, Murphy KM \& O'Garra A. Dendritic cells produce IL-12 and direct the development of Th1 cells from naïve $\mathrm{CD} 4^{+} \mathrm{T}$ cells. Journal of Immunology, 1995;154:5071-5079.

10. Pfeiffer S, Gooding RP, Apperley JF, Goldschmidt $\mathrm{H}$, Samson D. Dendritic cells generated from the 
blood of patients with multiple myeloma are phenotypically and functionally identical to those similarly produced from healthy donors. Br J Haematol., 1997;98(4):973-82.

11. Raje N, Gong J, Chauhan D, Teoh G, Avigan D, Wu Z, Chen D, Treon SP, Webb IJ, Kufe DW, Anderson KC. Bone marrow and peripheral blood dendritic cells from patients with multiple myeloma are phenotypically and functionally normal despite the detection of Kaposi's sarcoma herpesvirus gene sequences. Blood. 1999;93:1487-95.

12. Ratta M, Fagnoni F, Curti A, Vescovini R, Sansoni P, Oliviero B, Fogli M, Ferri E, Della Cuna GR, Tura S, Baccarani M, Lemoli RM. Dendritic cells are functionally defective in multiple myeloma: the role of interleukin-6. Blood, 2002;100(1):230-7.

13. Rissoan MC, Soumelis V, Kadowaki N, Grouard G, Briere F, de Waal Malefyt R. \& Liu YJ. Reciprocal control of $\mathrm{T}$ helper cell and dendritic cell differentiation. Science, 1999;283:1183-1186.

14. Robinson SP, Patterson S, English N, Davies D, Knight SC \& Reid CD. Human peripheral blood contains two distinct lineages of dendritic cells. European Journal of Immunology, 1999;29:2769-2778.

15. Shortman K \& Caux C. Dendritic cell development: multiple pathways to nature's adjuvants. Stem Cells, 1997;15:409-419.

16. Tarte K, Lu ZY, Fiol G, Legouffe E, Rossi JF, Klein B. Generation of virtually pure and potentially proliferating dendritic cells from non-CD34 apheresis cells from patients with multiple myeloma. Blood, 1997;90(9):3482-95.

17. Xie J, Wang Y, Freeman ME 3rd, Barlogie B, Yi Q.Beta 2-microglobulin as a negative regulator of the immune system: high concentrations of the protein inhibit in vitro generation of functional dendritic cells. Blood. 2003 May 15;101(10):4005-12. 